\title{
On Linguistics and Translation
}

B.N. Patnaik

Retired Professor of English and Linguistics, IIT Kanpur

(The written and edited version of the talk given on June 16, 2012 in NTM library)

In my early twenties, at SCS College, Puri, I used to teach a remarkable book by Bertrand Russell to the final year BA students: The Impact of Science on Society. Talking about what is not the scientific attitude, Russell gave the following example. Aristotle's view was that women have fewer teeth than men. Russell draws attention to the fact that the great philosopher had married four times, but it had never occurred to him to count the teeth of his wives to see whether indeed his assertion about women's teeth was substantiated by what he had observed. He never cared to test things which were easily testable. He was the quintessential Greek, who loved to think and hated to do things. Now you might ask what relevance all this has to the topic of discussion this afternoon, which is whether linguistics is necessary for translation, whether a practising translator needs linguistics. It has, as we will see.

One is tempted to answer the question in the negative, going by at least what the translators generally say. Incidentally, I know a brilliant person who teaches literature and is an accomplished translator and a translation scholar, and who once raised a similar question in a seminar talk with respect to translation theory and translation. He suggested that translator is not helped by translation theory in the least. There are translation theorists who can't translate a page and there are competent translators who are completely ignorant of translation theory. Similarly, one would observe that there are linguists who can't translate and there are translators who have no knowledge of linguistics. Therefore our answer in the negative to the questions posed above about the role of linguistics in translation appears to be correct. It is of course entirely possible 
that there are translation theorists who are competent translators and there are linguists who are good translators but such facts prove nothing and do not persuade us to reconsider of our view.

In this connection let us have a little test here. Here is a short extract on Pele, the celebrated footballer, from Eduardo Galeano's fascinating book Soccer in Sunshine and Shadow, the most readable book on football ever written, in my opinion. It is a "knowledge text", but let us not go into the question of whether kavya expresses knowledge like shastra does; in other words whether poetry and fiction create and disseminate knowledge like scholarly texts do, and let us for the present, without argument, understand the term in the sense in which it is used in the NTM documents. In this extract there is information about Pele and there is a perspective that organizes this information. What is to be noted is that it is written in a literary style, and not the academic style in which knowledge texts are generally written. Now, I assume that we are all linguists here, so let's each of us translate the extract and see for ourselves how much of our knowledge of linguistics we are using in doing so.

A hundred songs name him. At seventeen he was champion of the world and king of soccer. Before he was twenty the government of Brazil named him a "national treasure" that could not be exported. He won three world championships with the Brazilian team and two with the club Santos. After his thousandth goal, he kept counting. He played more than thirteen hundred matches in eighty countries, one game after another at a punishing rate, and he scored nearly thirteen hundred goals. Once he held up a war: Nigeria and Biafra declared a truce to see him play. To see him play was worth a truce and a lot more. When Pele ran hard he cut right through his opponents like a hot knife through butter. When he stopped, his opponents got lost in the labyrinths his legs embroidered. When he jumped, he climbed into the air as if there were a staircase. When he executed a free kick, his opponents in the wall wanted to turn around to face the net, so as not to miss the goal. He was born in a poor home in a faroff village, and he reached the summit of power and fortune where blacks were not allowed. Off the field he never gave a minute of his 
time and a coin never fell from his pocket. But those of us who were lucky enough to see him play received alms of extraordinary beauty: moments so worthy of immortality that make us believe immortality exists.

Consider the first sentence: "A hundred songs name him." How should we translate "a hundred"? Surely not literally, because in this sentence it has the sense of "many", "a considerable number", etc. So what word should we choose - a quantifier, anek (many) or a reduplicative saha saha (hundred hundred, i.e., hundreds)? How should we translate "song"? Literally, as a poetic composition that can be sung? Presumably not. When we translate the sentence should we ignore the rhetoric and simply capture the essential meaning of the sentence in our translation - that he is a big celebrity? A superstar of football, whose name occurs in many discourses? But this way, shall we not end up using a rather flat sentence? Consider the phrase "where blacks are not allowed". Would passive appear more natural in our language? But if we use something like "where blacks do not or cannot reach" instead, it would not express the idea that the blacks are discriminated against and are denied opportunities. Thus there is tension between elegance of expression and compromise with the totality of meaning. Notice that we have mentioned two kinds of problems here: we might call one of these "local", which is the problem of lexical choice for a particular lexical item in the sentence, and the other, "global", which relates to various choices including the stylistic one ranging over the whole sentence (in fact, the discourse). There is nothing or very little of linguistics that seems useful when we consider the translation questions mentioned above. One might think that of all branches of linguistics, it is sociolinguistics which is most useful for a translator since there is a clear sociolinguistic dimension to lexical choice (for instance does the translator choose a colloquial word from the standard variety of the target language or a Sanskritized word?). But it could be argued that this view does not necessarily lead to the conclusion that the translator must study sociolinguistics to translate better. Whatever knowledge of the lexical system of a language is of relevance here, a translator knows the same by being a competent user of the language. In sum, we arrive 
at the conclusion that a translator is not benefitted by knowledge of linguistics when it comes to translation.

Before proceeding further, we would state the following. Suppose it is established conclusively that linguistics does not contribute to translation or has no reliable application whatsoever, it does not undermine value or importance of the discipline in any way at all. There is no evaluation criterion for a theoretical enterprise to the effect that it must have an application. If it turns out that it has indeed an application, it need not be taken as a value addition to the enterprise. There is this interesting example of the famous mathematician, Professor Hardy, who felt proud that his mathematical work had no application. Luckily for him it was only after his death that application was found of his work. One could call him a "theoretical purist", who believed in knowledge for knowledge's sake, and felt that an idea lost its purity when an application was found for it. There may not be many buyers today for the theory of knowledge for knowledge's sake, but that does not justify the incorporation of a criterion to the evaluation matrix to the effect that an idea which has application is more highly valued than another which has no known application. So if translation does not benefit at all from linguistics, it is not a weakness or inadequacy of linguistics. Similarly if translation theory does not help a practising translator, it may not be seen as a negative comment on translation theory.

Let us now consider some of what can be called translation practices as we construct them from some of the main ideas of linguists on translation. One (J.C.Catford's) is essentially of finding equivalents in the target language of units of say, a sentence in the source language, and constructing the sentence in the target language by using the method of substitution and making suitable modifications in the ordering of elements at the level of syntactic structure so that the translated version does not violate the permissible order of constituents in the target language. Thus when a sentence of English is translated into Hindi, then these modifications must ensure that the output has the SOV structure, not the SVO structure. It would appear that the main ideas of this theory of translation are 
based on a commonsensical understanding of the act of translation, but it is not meant to be a criticism of the theory. This was perhaps the first linguistic theory of translation and very little of significance about translation was known at that time for a linguist to construct a sophisticated theory of the same. Turning to Eugene Nida, a well known name in the field, he correctly questioned the viability of the above, but his theory of translation was more like his thoughts on what goes on in the translator's mind, derived from the broad approach to the question of form and meaning of a sentence as explicated in Noam Chomsky's Syntactic Structures and Aspects of the Theory of Syntax. A translator arrives at the meaning of the source language sentence and then tries to express it in the target language using the resources - lexical, syntactic, etc. - of the latter. Despite obvious differences from Catford's ideas on translation, when it comes to the level of technology and implementation, there does not really seem to be much difference between Nida and Catford. In terms of Catford's theory, one could translate the first sentence of the extract in Odia as ek saha geetare tanka naama achi (his name occurs in a hundred songs) or some variation of it, and I do not see how Nida's theory would yield a significantly different text, because the meaning of the source language sentence on which the translator would work in terms of his theory would be in some sense the "basic meaning" of the sentence, not the "total meaning" of it, which would include pragmatic, stylistic meanings as well as the various nuances, if one has to think of Nida's as an explicit or at least a potentially explicit theory and not a statement of the commonsensical understanding of the translation process.

Translation does not seem to have ever been among the preoccupations of the study of language. If we conceptualize the study of language rather comprehensively, then arguably the activity of making bilingual dictionary, which is a form of translation at the lexical level, would count as part of the linguistic enterprise. As far as India is concerned, preparation of bilingual dictionaries is about two hundred years old. It seems to have started with the missionaries' effort to make such dictionaries involving English and Indian languages. As for the study of the grammatical (including 
phonological) systems from a comparative perspective, linguists seem to have started working on the same in the last century when the idea of mother tongue interference in foreign language learning gained some acceptance among those involved in foreign language teaching. Now an approach to translation based on bilingual dictionaries would view it as mainly an activity of finding equivalents in the target language of the words of a sentence of the source language.

One could say that translation as we understand the term today is only a two hundred year old activity in India. Earlier there were retelling, adaptation and the like, which involved significant modifications of the source material. The celebrated Odia poet Sarala Dasa did not translate Vyasa's Mahabharata, but retold it. The Odia poet Balarama Dasa did not translate the Ramayana; he retold it. Translation started with the missionaries rendering the Bible into Indian languages, and soon after that, preparing bilingual dictionaries. Although the missionary-translators themselves did not know the target language, they knew that a competent translator must know the source and the target languages well. What they did to overcome their lack of knowledge of the target language need not concern us here.

A word here about what it means to know a language well in the context of the present discussion. One can be said to know a language well if one knows the near-total meaning (not merely the basic meaning) of expressions of that language in various contexts of use and also when de-contextualized. To take a few examples, one must know that in particular contexts of use the sentence "tea will be served at 4 O'clock" would be interpreted as an invitation or just a piece of information. He must also know that with or without any context "everyone in this room voted in an election" would have ambiguous interpretation: the election could be the same or different for the voters concerned. Incidentally, a translation of this sentence into an Indian language following Catford's approach would not retain the ambiguity of the original because the article modifying "election" has only the numeral interpretation in our languages. A 
competent translator would also know that "look, Rambha is coming" is ambiguous and in a certain context it would be understood as an ironical and crude remark on the girl under reference.

As mentioned above, a person who knows both the source and the target languages in the above sense of "know" is eminently suitable for undertaking translation. Concerning the challenges that a translator faces, Manoj Das, the eminent Odia writer, who writes in both Odia and English, and is a very competent translator as well, says in his introduction to "The Escapist" that the biggest challenge the translator faces is finding lexical equivalents. To take a very simple example, if one translates gangaa jal, an expression of Hindi as "the waters of the Ganga" in English, one has not captured a significant part of the meaning(that the waters of the Ganga are spiritually purifying, etc.) of the Hindi expression, if the context of use of the same is religious. Perhaps the translator would have to add an explanatory note. Lexical items often have connotative meaning, laksana (suggestive) meaning as the ancient Indian scholars of meaning called it. Sometimes connotations of the lexical items have to do with the culture in which the relevant language is used. Any translator knows that the problem of finding lexical equivalents is not restricted to the literary texts. It is just that in the context of the knowledge texts it becomes a problem of creating equivalent terms. All this is too familiar to merit any discussion.

To mention the obvious, in real life, one does not translate only sentences (except perhaps as a pedagogical exercise); one translates texts. The translation should be such that it must sound natural in the target language. Of course artificiality in translation cannot be entirely eliminated, be it a literary text or a knowledge text. It is especially true of the latter and in particular, when it is a scientific text, if the translation is into a language that does not have the necessary technical terms and for that reason lacks a tradition of discourse on scientific topics. One of the problems of the translator of a literary text is how much artificiality he can allow in his translation; sometimes he might decide that the best strategy for that text is not translation but adaptation. Incidentally, knowledge texts are not 
entirely culturally independent; it is a matter of degree - a higher level scientific text is more independent in the intended sense than say, a human science text at the same level. It must not be forgotten that all discourses are created in a culture.

Now, the discussion so far suggests that linguistics has no role to play in translation; putting it more specifically, one does not need knowledge of linguistics to translate, be it any kind of text. Let us reconsider this view, drawing from a certain domain which is not usually brought into the ambit of a discussion on this question. What we have in mind is Machine Translation.

Consider devising a MT system that would translate "He saw her with a telescope" into an Indian language. This sentence is ambiguous; in one interpretation "with the telescope" is associated with "see" and in the other, with "the girl". In the first, the phrase is interpreted as bearing the "instrument" relation with the verb, in the second, it is in a modifier relation with the object of the verb - it identifies a particular girl from a set of girls, namely, the one who has a telescope. The preposition "with" expresses both relations. In our languages, there is no case marker / post-position with the relevant features of "with". In Odia, for instance, the instrumental marker is $d$ wara. The sentence in the other meaning will be translated very differently, say, with a restrictive relative clause, modifying the object of "see" (i.e., "the girl"). Thus the sentence would have two realizations in the Indian language translation.

In order to translate the sentence, broadly speaking, the system has to recognize, among others, that it has two meanings and what precisely these are. Then, using the grammar of English, it must parse the sentence and arrive at two configurations, each capturing a meaning. Then it has to look for lexical equivalences in the target language and also identify how the two distinct relations mentioned above are realized in the same. These are highly complex tasks and each has a number of sub-tasks. For instance, parsing would involve identification of the category of each of the words, assignment of phrase structure, identification of the subject, object and adjunct in the sentence, morphological analysis of the words (how else would 
one know what the tense of the sentence is?) in the sentence, etc.

The system can perform these tasks, which are some of the sub-tasks of translation, only if the relevant knowledge is fed into it. And this obviously is linguistic knowledge, which is the subject matter of linguistics. Now a system of the kind under reference is only an automatization of what man does; the MT system is an automatization of what the human translator does. Granted that this statement requires qualifications, especially at the level of detail, there is no reason to assume that the basic assertion is misleading.

Thus the translator uses linguistic knowledge, but he is unaware of it. This is not surprising; it is well known that a oneyear old child, for example, uses linguistic knowledge to understand what his parents tell him, and tell his mother what he wants. He is unaware that he uses a complex and sophisticated knowledge system in order to interact with his parents and whosoever cares to speak to him and listen to him. Linguistics as a discipline only tries to state that knowledge in explicit terms. No language activity - from conversation to translation - is possible without the said knowledge. However it seems that we become aware of it when we reflect, not on the human translator and what we think he does when he is engaged in the act of translation, but on machine translation.

The machine gets the linguistic knowledge from linguists, so one who is engaged in creating that knowledge to be fed into the computer has to learn linguistics. Where does the human translator get that knowledge from, which he uses although he is unaware of it? He gets it in the same way the child gets it to function in the linguistic world: from what is given him as part of his biological endowment and from his linguistic environment, which for the translator (in comparison with the child's) is immensely rich - he has a highly educated adult's knowledge of the languages concerned and has read literature of all kinds in both these languages. $\mathrm{He}$ uses linguistic knowledge to translate, and if he is curious to know consciously what he already knows but is not aware that he does, he has to do linguistics. 